(A) Check for updates

Cite this: Food Funct., 2018, 9, 5417

\section{Characterization of phenolic compounds in tincture of edible Nepeta nuda: development of antimicrobial mouthwash}

\author{
Marija Smiljković, (ID a Maria Inês Dias, (iD b Dejan Stojković, (D) a Lillian Barros, (D) b \\ Danka Bukvički, ${ }^{c}$ Isabel C. F. R. Ferreira (D) *b and Marina Soković (DD *a
}

\begin{abstract}
The activity of edible Nepeta nuda L. (Lamiaceae) tincture and Listerine towards a selected group of oral pathogenic microorganisms ( 4 bacterial and 9 fungal strains) has been explored. Their potentials to inhibit the formation of biofilm and to diminish established biofilm have been compared. The amount of $N$. nuda tincture and swishing time necessary for reaching better or equivalent antimicrobial effect than that of Listerine have been predicted. Phenolic compounds in N. nuda tincture are determined by LC-DAD/ ESI-MSn. Both Listerine and N. nuda tincture possess good antimicrobial potentials (MIC in the range of 0.8-15 $\mu \mathrm{L}$ per well) including inhibition of biofilms. Rosmarinic acid and verminoside are the most dominant phenolic compounds present in the $N$. nuda tincture. Based on in vitro results, we infer that it is more desirable to swish $20 \mathrm{~mL}$ of mouthwashes (Listerine and $\mathrm{N}$. nuda tincture, $100 \mathrm{mg} \mathrm{mL}^{-1}$ ) for $30 \mathrm{~s}$ when dealing with selected microorganisms in general and for $60 \mathrm{~s} \mathrm{(} N$. nuda tincture) when dealing with bacterial biofilms.
\end{abstract}

Received 21st July 2018

Accepted 17th September 2018

DOI: $10.1039 / \mathrm{c} 8 \mathrm{fo} 01466 \mathrm{c}$

rsc.li/food-function

\section{Introduction}

Nepeta genus (Lamiaceae) is distributed in Europe and Asia and has more than 280 species including Nepeta nuda L. (syn. Nepeta pannonica L.). Nepeta species are used in ethnomedicine for their beneficial effects such as antispasmodic, diuretic, antiseptic, antitussive, antiasthmatic, and febrifuge. ${ }^{1}$ Different species of Nepeta genus have been proven to have antimicrobial activity: Nepeta cataria, Nepeta elliptica, Nepeta rtanjensis, Nepeta sibirica, Nepeta nervosa, Nepeta leucophylla, Nepeta ciliaris, Nepeta clarkei, Nepeta ucrainica ssp. kopetdaghensis, Nepeta sintenisii. ${ }^{2}$ N. nuda leaves together with the leaves and aerial parts of Nepeta italica and Nepeta trachonitica have been used in Turkey as tea. ${ }^{3}$

The chemical constituents of Nepeta genus include various secondary metabolites: terpenes, phenols, polyphenols and steroids. Nepeta genus has various flavonoid classes (flavones, flavonols, flavanols and flavanone) with flavones being used as

\footnotetext{
"University of Belgrade, Institute for Biological Research "Sinisa Stankovic", Bulevar Despota Stefana 142, 11000 Belgrade, Serbia.E-mail: mris@ibiss.bg.ac.rs; Fax: +381-11-2761433; Tel: +381-11-2078419

${ }^{b}$ Centro de Investigação de Montanha (CIMO), Instituto Politécnico de Bragança, Campus de Santa Apolónia, 5300-253 Bragança, Portugal.E-mail: iferreira@ipb.pt; Fax: +351-273-325405; Tel: +351-273-303219

${ }^{c}$ University of Belgrade, Faculty of Biology, Institute of Botany and Botanical Garden "Jevremovac", 11000 Belgrade, Serbia
}

specific markers in chemotaxonomic identification of the genus. They are also known to have more than 20 different polyphenolics (gallic acid, ferulic acid, $p$-coumaric acid, 4-hydroxybenzoic acid, caffeic acid, rosmarinic acid and others). ${ }^{2}$

Chronic inflammations in oral cavity are induced by the activity of bacteria and can subsequently lead to the development of periodontal diseases; different harmful consequences could appear if these bacteria leave original sites of infection within oral cavity and settle elsewhere within the body. ${ }^{4}$ Oral cavity can be the source of oral malodor due to bacterial overgrowth and food decay; bacterial species associated with both periodontitis and gingivitis are linked to this unpleasant condition. ${ }^{5}$ Bacterial ability to form biofilms on the tooth surface, i.e., dental plaque is a factor that increases possibility for the development of both caries and periodontitis. ${ }^{6}$ Bacterial plaque can be removed with tooth brushing and dental floss, but usage of mouth rinse could be one more step towards complete control of this problem.

Enterococcus faecalis species are not among the bacterial species that are found as a part of general oral microbiota, but they are the most frequently isolated bacteria after failed endodontic treatment. Their presence is being linked to secondary endodontic infections caused by the formation of bacterial biofilms. $^{7}$ E. fecalis is also associated with periodontal disease, ${ }^{8}$ whereas Streptococcus mutans and Streptococcus sali- 
varius overgrowth is linked to dental caries. ${ }^{9,10}$ Streptococcus pyogenes can cause variety of infections, which are all initiated by adhesion to human epithelial cells; this is a reason to search for medicine that could prevent this initial adhesion. If the initial adhesion is not prevented, a wide range of conditions can result including pharyngitis and necrotizing fascitis. $^{11}$

The species that belong to Candida genus are found as commensal microorganisms in oral cavities of healthy people, but under diverse immunocompromising conditions, they can overgrow and cause serious infections. Infections can range from mild oral thrush towards discomfort in mastication and limiting nutrition, whereas in the worst case scenario, these fungi can settle in the bloodstream and cause highly lethal candidemia. $^{12,13}$

Accordingly, the aim of the present study was to investigate the antimicrobial potential of $N$. nuda tincture, standardize its active concentration in tincture and determine its chemical composition regarding phenolic compounds that could be linked with the antimicrobial activity of tincture against microorganisms related to oral infections. We examined in vitro whether the tincture of Nepeta nuda could be used as an alternative to Listerine for the treatment and prevention of oral diseases caused by a selected group of pathogenic microorganisms and which one of these two would be a better choice when dealing with pathogens from oral cavity.

\section{Materials and methods}

\subsection{Plant collection}

The samples of wild growing Nepeta nuda L. were collected from mountain Tara, Serbia, in summer 2013, and authenticated by Dr Milan Veljić (Faculty of Biology, University of Belgrade). The samples were lyophilized (LH Leybold, Lyovac GT2, Frenkendorf), reduced to a fine-dried powder (20 mesh), stored in a desiccator, and protected from light until further analysis.

\subsection{Listerine ${ }^{\circledR}$}

Listerine - cool mint was purchased from a local drugstore. It was stated on the label that it reduces up to $70 \%$ more plaque than brushing alone. The ingredients marked on the label were water, alcohol, sorbitol, poloxamer 407, benzoic acid, sodium saccharin, eucalyptol, aroma, methyl salicylate, thymol, menthol, sodium benzoate, CI 42053.

\subsection{Tincture preparation}

A plant sample was air dried and cut into small pieces; $10 \mathrm{~g}$ of the plant material was extracted using $300 \mathrm{~mL}$ of methanol (Merck, Germany) at $-20{ }^{\circ} \mathrm{C}$ overnight. The extract was sonicated for $15 \mathrm{~min}$ and filtered through Whatman No. 4 paper. The plant residue was re-extracted using another $300 \mathrm{~mL}$ of methanol, and the procedure was repeated. The obtained methanol extract was evaporated at $40{ }^{\circ} \mathrm{C}$ on a rotary evaporator (Büchi R-210) to dryness, and the dried extract was dissolved in $30 \%$ ethanol (Merck, Germany) to obtain a tincture in a final concentration of $50 \mathrm{mg} \mathrm{mL}^{-1}$.

\subsection{Antimicrobial activity}

2.4.1. Microorganisms and culture conditions. The following bacterial strains were used: Streptococcus mutans (IBR S001), Streptococcus pyogenes (IBR S004), Streptococcus salivarius (IBR S006) and Enterococcus faecalis (IBR E001); these bacteria were maintained on Tryptic Soy Agar (Torlak, Serbia). Candida sp. isolates used in this study were C. albicans 475/15, C. albicans 16/15, C. albicans 17/15, C. albicans 532/15, C. albicans 27/15, C. albicans ATCC 10231, C. krusei H1/16, C. krusei MN13, and C. glabrata 4/6/ 15. They were obtained by rubbing sterile cotton swabs from oral cavities of patients at Otorhinolaryngology clinic at Clinical Hospital Center Zvezdara, Belgrade, Serbia and determined on CHROMagar plates (Biomerieux, France), whereas C. albicans ATCC 10231 was purchased. Fungal strains were maintained on Sabourand dextrose agar (Torlak, Serbia). Microorganisms tested were deposited at the Mycological Laboratory, Department of Plant Physiology, Institute for Biological Research "Siniša Stankovic", University of Belgrade.

2.4.2. Microdilution assay. Minimum inhibitory (MIC) and minimum bactericidal/fungicidal (MBC/MFC) concentrations were determined by the microdilution method in 96 well microtiter plates (Spektar, Cacak). ${ }^{14,15}$ MICs were observed as the lowest concentrations without visible bacterial/fungal growth. MBCs/MFCs were determined by serial sub-cultivation of $10 \mu \mathrm{L}$ into microtiter plates containing $100 \mu \mathrm{L}$ of broth per well and further incubation at $37^{\circ} \mathrm{C}$ for $24 \mathrm{~h}$. The lowest concentration with no visible growth was defined as MBC/MFC, indicating $99.5 \%$ killing of the original inoculum. The results were compared in $\mu \mathrm{L}$ per well since the concentrations of the active ingredients in Listerine were not visible from the label; therefore, it was chosen to present results based on the volume of the liquids. Also, 3.75\% ethanol was used as a negative control.

2.4.3. Inhibition of biofilm formation. The ability of N. nuda tincture and Listerine to inhibit biofilm formation was determined as described previously with some modifications. ${ }^{16,17}$ S. pyogenes and E. faecalis cells were incubated in 96 well microtiter plates with adhesive bottom (Sarstedt, Germany) with MIC and sub-MIC concentrations of the compounds in Triptic soy broth enriched with $2 \%$ glucose at $37^{\circ} \mathrm{C}$ for 24 hours. After 24 hours, each well was washed twice with sterile PBS (Phosphate buffered saline, $\mathrm{pH}$ 7.4), and biofilms were fixed with methanol for $10 \mathrm{~min}$; next, methanol was removed and the plate was air dried. The biofilm was stained with $0.1 \%$ crystal violet (Bio-Merieux, France) for $30 \mathrm{~min}$. Wells were washed with water, air dried and $100 \mu \mathrm{L}$ of $96 \%$ ethanol (Zorka, Serbia) was added to dissolve bound crystal violet. The absorbance was read at $620 \mathrm{~nm}$ on a Multiskan ${ }^{\mathrm{TM}}$ FC Microplate Photometer, Thermo Scientific ${ }^{\mathrm{TM}}$. The percen- 
tage of inhibition of biofilm formation was calculated by the formula:

$$
\left[\left(\mathrm{A}_{620} \text { control }-\mathrm{A}_{620} \text { sample }\right) / \mathrm{A}_{620} \text { control }\right] \times 100 .
$$

\subsection{Prediction of tincture application as mouthwash liquid in comparison with Listerine}

2.5.1. Recommended volume of mouthwash for swishing. It is recommended that $20 \mathrm{~mL}$ of liquid should be swished when using Listerine. The amount of tincture necessary for the same antimicrobial effect as that of $20 \mathrm{~mL}$ of Listerine was calculated for every microorganism taking into account $\mathrm{MBC} /$ MFCs obtained in the in vitro experiment.

2.5.2. Recommended duration of swishing. E. faecalis and C. albicans $17 / 15$ were selected as bacteria and fungi with the highest MBC/MFC observed since the antimicrobial effect obtained for other microorganisms was lower and it is supposed that the tincture will act on them as well. Microorganisms were incubated with MBC/MFC of mouthwashes in total volume of $100 \mu \mathrm{L}$, which was rubbed into agar plates with a sterile spreader after $30 \mathrm{~s}, 60 \mathrm{~s}, 90 \mathrm{~s}$ and $120 \mathrm{~s}$ of treatment. Plates were incubated at $37^{\circ} \mathrm{C}$, and the number of colonies was counted after $24 \mathrm{~h}$.

E. faecalis species were grown for $24 \mathrm{~h}$ at $37^{\circ} \mathrm{C}$ in Triptic soy broth enriched with $2 \%$ glucose in microtiter plates with adhesive bottom. Wells were washed twice with sterile PBS and the remaining biofilm was treated for $30 \mathrm{~s}$ (recommended time for mouth swishing with Listerine) and $60 \mathrm{~s}$ with both Listerine and $N$. nuda tincture at MIC and 1/2 MIC values. The wells were washed; the remaining biofilm was fixed with methanol and after air drying, it was stained with $0.1 \%$ crystal violet. After dissolving the stain in ethanol, the absorbance was read and the percentage of biofilm diminishing was calculated as mentioned above.

\subsection{Characterization of phenolic compounds by LC-DAD-ESI/MSn}

The tincture was diluted to a concentration of $5 \mathrm{mg} \mathrm{mL}^{-1}$ and filtered through a $0.22 \mu \mathrm{m}$ disposable LC filter disk.
The chromatographic analysis was performed in a Dionex Ultimate 3000 UPLC (Thermo Scientific, San Jose, CA, USA) system equipped with a diode array detector (280, 330 and $370 \mathrm{~nm}$ as preferred wavelengths) and coupled to an electrospray ionization mass detector (Linear Ion Trap LTQ XL mass spectrometer, Thermo Finnigan, San Jose, CA, USA), as previously described by Bessada et al. ${ }^{18}$ The phenolic compounds were identified by comparing their chromatographic characteristics and spectral data with those obtained from standard compounds, when available. Otherwise, compounds were tentatively identified by comparing the obtained information with available data reported in the literature. For quantitative analysis, a 5-level calibration curve for each available phenolic standard (caffeic acid; protocatechuic acid; rosmarinic acid) was constructed based on the UV signal; when a commercial standard was not available, the quantification was performed using the most similar

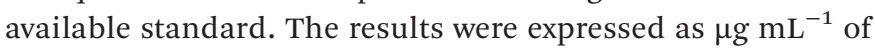
extract.

\section{Results}

\subsection{Antimicrobial activity}

In the microdilution assay, Listerine showed good antibacterial activity (the highest MIC was $15 \mu \mathrm{L}$ per well), but Nepeta nuda tincture turned out to be more efficient. The activity of $N$. nuda tincture towards all four bacterial strains tested was in the MIC range of 3.1-6.2 $\mu \mathrm{l}$ per well (Table 1). E. faecalis was the most resistant to the antibacterial treatment.

Antifungal treatment was even more effective and for the treatment of six fungal strains, Listerine and $N$. nuda possessed identical activities. Clinical isolates had MICs of $1.6 \mu \mathrm{L}$ per well, and C. albicans ATCC 10231 strain was more sensitive with MIC of $0.8 \mu \mathrm{L}$ per well for both mouthwashes. Nepeta nuda tincture was more effective for one C. krusei strain (MIC $0.8 \mu \mathrm{L}$ per well), whereas Listerine showed better activity

Table 1 Antimicrobial activity of two mouthwashes combating selected pathogens from oral cavity

\begin{tabular}{|c|c|c|c|c|}
\hline \multirow[b]{2}{*}{ Microorganisms } & \multicolumn{2}{|c|}{ Nepeta nuda tincture $50 \mathrm{mg} \mathrm{mL} \mathrm{m}^{-1}$} & \multicolumn{2}{|l|}{ Listerine } \\
\hline & MIC & MBC/MFC & MIC & $\mathrm{MBC} / \mathrm{MFC}$ \\
\hline S. mutans IBR S001 & $3.1 \pm 0.1^{\mathrm{a}}$ & $6.2 \pm 0.3^{c}$ & $15 \pm 1.0^{\mathrm{d}}$ & $30 \pm 2.0^{\mathrm{d}}$ \\
\hline S. pyogenes IBR S004 & $3.1 \pm 0.2^{\mathrm{b}}$ & $6.2 \pm 0.3^{c}$ & $15 \pm 0.8^{c}$ & $30 \pm 3.0^{\mathrm{e}}$ \\
\hline S. salivarius IBR S006 & $3.1 \pm 0.2^{\mathrm{b}}$ & $6.2 \pm 0.2^{\mathrm{b}}$ & $7.5 \pm 0.8^{c}$ & $15 \pm 2.0^{\mathrm{d}}$ \\
\hline E. faecalis IBR E001 & $6.2 \pm 0.3^{\mathrm{c}}$ & $12.5 \pm 1.0^{\mathrm{d}}$ & $15 \pm 1.0^{\mathrm{d}}$ & $30 \pm 3.0^{\mathrm{e}}$ \\
\hline C. albicans 475/15 & $1.6 \pm 0.1^{\mathrm{a}}$ & $3.1 \pm 0.2^{\mathrm{b}}$ & $1.6 \pm 0.1^{\mathrm{a}}$ & $3.1 \pm 0.3^{\mathrm{c}}$ \\
\hline C. albicans $16 / 15$ & $1.6 \pm 0.1^{\mathrm{a}}$ & $3.1 \pm 0.2^{\mathrm{b}}$ & $1.6 \pm 0.1^{\mathrm{a}}$ & $3.1 \pm 0.3^{\mathrm{c}}$ \\
\hline C. albicans $17 / 15$ & $3.1 \pm 0.3^{\mathrm{c}}$ & $6.2 \pm 0.2^{\mathrm{b}}$ & $1.6 \pm 0.2^{\mathrm{b}}$ & $3.1 \pm 0.2^{\mathrm{b}}$ \\
\hline C. albicans $532 / 15$ & $1.6 \pm 0.1^{\mathrm{a}}$ & $3.1 \pm 0.3^{\mathrm{c}}$ & $1.6 \pm 0.2^{\mathrm{b}}$ & $3.1 \pm 0.2^{\mathrm{b}}$ \\
\hline C. albicans $27 / 15$ & $1.6 \pm 0.1^{\mathrm{a}}$ & $3.1 \pm 0.3^{c}$ & $1.6 \pm 0.1^{\mathrm{a}}$ & $3.1 \pm 0.2^{\mathrm{b}}$ \\
\hline C. albicans ATCC 10231 & $0.8 \pm 0.1^{\mathrm{a}}$ & $1.6 \pm 0.2^{\mathrm{b}}$ & $0.8 \pm 0.1^{\mathrm{a}}$ & $1.6 \pm 0.1^{\mathrm{a}}$ \\
\hline Candida krusei $\mathrm{H} 1 / 16$ & $1.6 \pm 0.2^{\mathrm{b}}$ & $3.2 \pm 0.2^{\mathrm{b}}$ & $1.6 \pm 0.1^{\mathrm{a}}$ & $3.1 \pm 0.2^{\mathrm{b}}$ \\
\hline C. krusei MN13 & $0.8 \pm 0.1^{\mathrm{a}}$ & $1.6 \pm 0.1^{\mathrm{a}}$ & $1.6 \pm 0.2^{\mathrm{b}}$ & $3.1 \pm 0.2^{\mathrm{b}}$ \\
\hline C. glabrata 4/6/15 & $3.1 \pm 0.2^{\mathrm{b}}$ & $6.2 \pm 0.3^{c}$ & $1.6 \pm 0.2^{\mathrm{b}}$ & $3.1 \pm 0.3^{\mathrm{c}}$ \\
\hline
\end{tabular}

MIC - minimum inhibitory concentration. MBC/MFC - minimum bactericidal/fungicidal concentration. The results are expressed in $\mu$ l per well. Values are expressed as means \pm SD. In each row, different letters mean significant differences between samples $(p<0.05)$. 
towards C. albicans 17/15 (MIC $1.6 \mu \mathrm{L}$ per well) and C. glabrata 4/6/15 (MIC $1.6 \mu \mathrm{L}$ per well) (Table 1).

\subsection{Antibiofilm activity}

$N$. nuda showed much stronger potential to inhibit the formation of bacterial biofilms. The most promising antibiofilm concentration 1/2 MIC could be distinguished since $N$. nuda tincture at that concentration inhibited the formation of S. pyogens biofilm for $84 \%$ and E. faecalis biofilm for $88 \%$. Listerine was more efficient in stopping biofilm formation of E. faecalis (1/2 MIC inhibited it for 58\%) than that of S. pyogenes (1/2 MIC inhibited it for $33 \%)$, which was still lower when compared with the activity of $N$. nuda tincture (Fig. 1A).

The impact of both mouthwashes on E. faecalis-established biofilm was tested. Listerine exhibited better activity in both concentrations after $30 \mathrm{~s}$ of treatment since it caused biofilm destruction of $39 \%$ (MIC) and 30\% (1/2 MIC), which was in accordance with that observed after its recommended swishing time of $30 \mathrm{~s}$, as marked on the label (Fig. 1B). N. nuda tincture had higher potential for the destruction of the formed biofilm after $60 \mathrm{~s}$ treatment; it caused 45\% (MIC treatment) and 25\% (1/2 MIC treatment) of biofilm reduction when compared to $23 \%$ and $24 \%$ of biofilm reduction after $30 \mathrm{~s}$.

\subsection{Prediction of quantity and time needed to swish $N$. nuda tincture to obtain the desirable antimicrobial effect}

The amount of $N$. nuda tincture necessary for reaching identical antimicrobial effect as that of $20 \mathrm{~mL}$ of Listerine was examined (Table 2). The volume needed for antibacterial effect

A

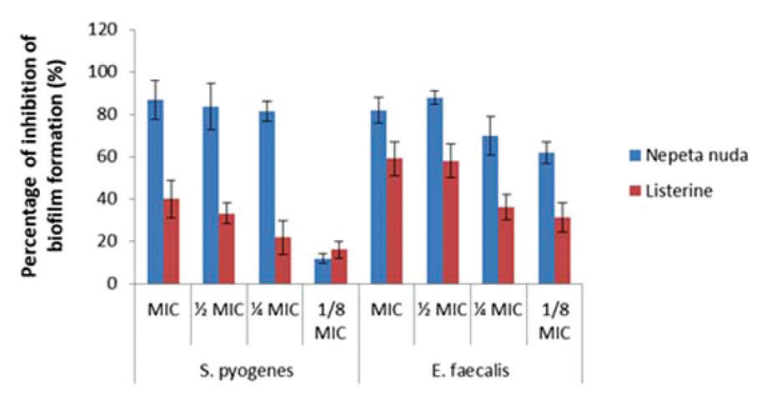

B

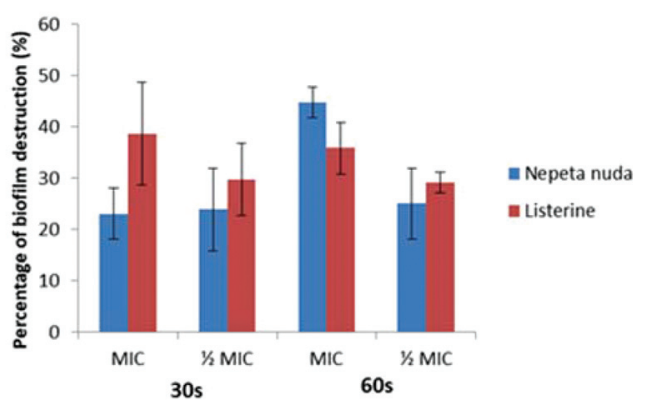

Fig. 1 (A) Percentage of inhibition of biofilm formation after treatment with MIC and subMIC of N. nuda tincture and Listerine. (B) Destruction of $E$. faecalis 24 hours formed biofilm after 30 and 60 seconds treatment with $N$. nuda tincture and Listerine expressed as inhibition percentage.
Table 2 Predicted volume to swish $N$. nuda tincture (dissolved extract 50 and $100 \mathrm{mg} \mathrm{mL}^{-1}$ ) to reach identical antimicrobial effect as that of $20 \mathrm{~mL}$ Listerine

\begin{tabular}{|c|c|c|}
\hline Microorganisms & $\begin{array}{l}\text { Volume of tincture } \\
50 \mathrm{mg} \mathrm{mL}^{-1}(\mathrm{~mL})\end{array}$ & $\begin{array}{l}\text { Volume of tincture } \\
100 \mathrm{mg} \mathrm{mL}^{-1}(\mathrm{~mL})\end{array}$ \\
\hline S. mutans IBR S001 & 4 & 2 \\
\hline S. pyogenes IBR S004 & 4 & 2 \\
\hline S. salivarius IBR S006 & 8 & 4 \\
\hline E. faecalis IBR E001 & 8 & 4 \\
\hline C. albicans $475 / 15$ & 20 & 10 \\
\hline C. albicans $16 / 15$ & 20 & 10 \\
\hline C. albicans $17 / 15$ & 40 & 20 \\
\hline C. albicans $532 / 15$ & 20 & 10 \\
\hline C. albicans $27 / 15$ & 20 & 10 \\
\hline C. albicans ATCC 10231 & 20 & 10 \\
\hline C. krusei $\mathrm{H} 1 / 16$ & 20 & 10 \\
\hline C. krusei MN13 & 10 & 5 \\
\hline C. glabrata $4 / 6 / 15$ & 20 & 10 \\
\hline
\end{tabular}

(4-8 $\mathrm{mL}$ ) was lower than the one for antifungal activity (10-40 mL) of $N$. nuda tincture. A tincture amount of $20 \mathrm{~mL}$ was able to deal with $92 \%$ of the tested species, requiring stronger treatment only for C. albicans $17 / 15$. We could state that $20 \mathrm{~mL}$ is more than enough for reaching maximal antibacterial and satisfactory antifungal activity. The fact that $40 \mathrm{~mL}$ of tincture (dissolved as $50 \mathrm{mg}$ of extract per $\mathrm{mL}$ and applied as mouthwash) is enough to achieve the maximal desirable and assumed antimicrobial effect towards all tested pathogens and taking into account that $40 \mathrm{~mL}$ is uncomfortable to swish in mouth, the tincture should be properly standardized to contain $100 \mathrm{mg}$ of $N$. nuda extract per $\mathrm{mL} ; 20 \mathrm{~mL}$ of such tincture would be more comfortable for swishing (Table 2).

The recommended duration of swishing for Listerine is 30 S. E. faecalis and C. albicans $17 / 15$ were incubated for 30,60 , 90 and $120 \mathrm{~s}$ with two mouthwashes (Listerine and $N$. nuda tincture) to observe the number of colonies that will survive the treatment. E. faecalis showed the highest decrease in the number of colonies after $60 \mathrm{~s}$ treatment with both of them (Fig. 2A), whereas C. albicans 17/15 had lower number of colonies even after $30 \mathrm{~s}$ also for both of them (Fig. 2B). The treatment of bacterial biofilm showed that Listerine acts as a promising antibiofilm agent in $30 \mathrm{~s}$, whereas $N$. nuda had higher inhibition percentages after $60 \mathrm{~s}$. Taking into account all the experimental results, it would be more desirable to swish mouthwashes (Listerine and $N$. nuda tincture) for $30 \mathrm{~s}$ when dealing with selected microorganisms in general and for $60 \mathrm{~s}$ (N. nuda tincture) when dealing with bacterial biofilms.

\subsection{Chemical profiling of $N$. nuda tincture regarding phenolic composition}

The characterization of the phenolic compounds of Nepeta nuda tincture was performed by LC-DAD-ESI/MSn analysis, and the chromatographic and mass spectral data of the identified compounds are presented in Table 3. A total of fifteen compounds were identified: eight phenolic acid derivatives, six phenylethanoid glycoside derivatives and one unknown com- 
A

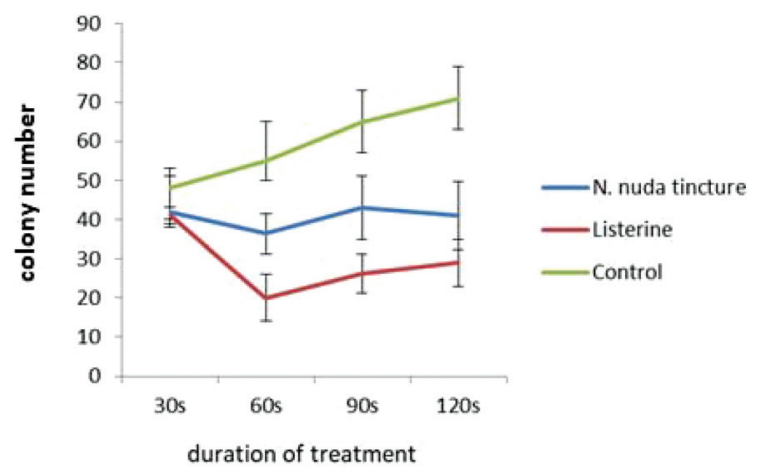

B

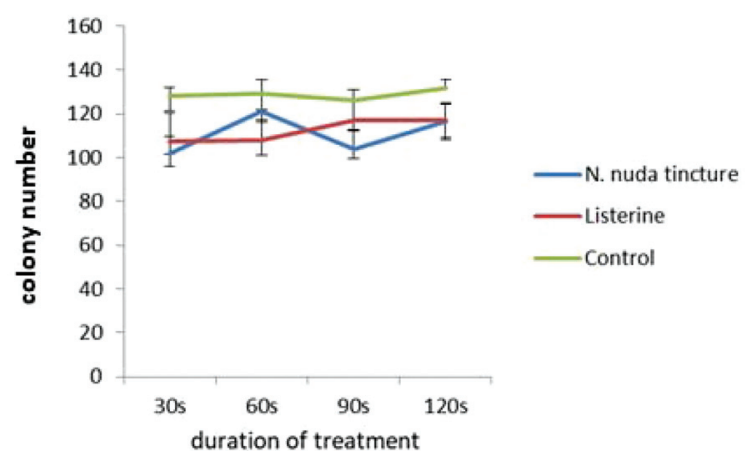

Fig. 2 Number of colonies growing after $30 \mathrm{~s}, 60 \mathrm{~s}, 90 \mathrm{~s}$ and $120 \mathrm{~s}$ treatment of $E$. faecalis (A) and C. albicans 17/15 (B) with N. nuda tincture and Listerine.

pound. The phenolic chromatographic profile recorded at $280 \mathrm{~nm}$ is presented in Fig. 3 .

Peaks 1, 4-7 and 9 were identified as phenylethanoid glycoside derivatives due to their MS2 fragmentation pattern and their UV-Vis characteristics. Peak $1\left([\mathrm{M}-\mathrm{H}]^{-}\right.$at $\left.m / z 685\right)$ was tentatively identified as ligstroside hexoside taking into account the findings described by Sanz et al. ${ }^{19}$ Similarly, peak $4\left([\mathrm{M}-\mathrm{H}]^{-}\right.$at $\left.m / z 637\right)$ was identified as eukovoside using the fragmentation described by Sanz et al. ${ }^{19}$ Peak $6\left([\mathrm{M}-\mathrm{H}]^{-}\right.$at $m / z$ 639) revealed five MS2 fragments at $m / z 477(-162 \mathrm{u}$, loss of a caffeoyl/hexosyl moiety), $m / z 315$ ( $-162 \mathrm{u}$, loss of caffeoyl/ hexosyl), and at $\mathrm{m} / \mathrm{z} 179, \mathrm{~m} / \mathrm{z} 161$ and $\mathrm{m} / \mathrm{z} 135$ (common to caffeic acid derivatives); this compound was identified as plantamajoside taking into account the findings reported by Gonda et al. ${ }^{20}$ and Živković et al. ${ }^{21}$ Peak $5\left([\mathrm{M}-\mathrm{H}]^{-}\right.$at $\mathrm{m} / \mathrm{z}$ 801) exhibited $162 \mathrm{u}$ higher than that of plantamajoside and a fragmentation spectrum similar to that of this compound, proposing tentative identification as a hexosyl derivative of plantamajoside. Peak $7\left([\mathrm{M}-\mathrm{H}]^{-}\right.$at $\left.m / \mathrm{z} 477\right)$ was tentatively identified as calcelarioside A/B1 taking into account the description by Sanz et al. (2012). Peak 9 ([M - H $]^{-}$at $m / z$ 523) was identified as verminoside taking into account the MS2 fragmentation patterns at $m / z 361$ ( $-162 \mathrm{u}$, possible hexosyl moiety loss), 179, 161 and 135 (characteristics of caffeic acid derivatives) and the description reported by Živković et al. ${ }^{21}$
The remaining compounds correspond to a caffeic acid dimer (rosmarinic acid, compound 12) as well as to other caffeic acid derivatives such as caffeic acid trimers (salvianolic acid A, compound 15 and 17) and tetramers (salvianolic acid $\mathrm{B}$, compound 10 and 15). The presence of rosmarinic acids has been reported previously in Nepeta nuda (syn. for Nepeta pannonica); ${ }^{22,23}$ thus, these type of derivatives, to the best of our knowledge, have not been previously described in this species.

Peak $2\left([\mathrm{M}-\mathrm{H}]^{-}\right.$at $\left.m / z 497\right)$ was associated to a protocatechuic acid derivative based on its UV spectra $\left(\lambda_{\max }\right.$ at 262 , sh296) and MS2 fragmentation $(\mathrm{m} / \mathrm{z} 153$, corresponding to protocatechuic acid). Regardless of detecting fragments with common losses such as that of hexosyl moieties $(\mathrm{m} / \mathrm{z} 335)$, an exact structure was not possible to achieve; therefore, it was tentatively assigned to protocatechuic acid derivative. Both compounds $11[\mathrm{M}-\mathrm{H}]^{-}$at $\left.m / z 519\right)$ and $8\left([\mathrm{M}-\mathrm{H}]^{-}\right.$at $m / z$ 453) were linked to a caffeic acid derivative based on the UV spectra and the MS2 characteristic fragments observed at $\mathrm{m} / \mathrm{z}$ 179 ([caffeic acid- $\mathrm{H}]^{-}$) and 135 ([caffeic acid- $\left.\mathrm{H}-\mathrm{CO}_{2}\right]^{-}$); their precise structures could not be concluded and therefore, they were identified as caffeic acid derivatives. Finally, compound 3 did not reveal a pseudomolecular ion although its MS2 fragmentation was coherent to that of rosmarinic acid; thus, it was tentatively assigned as a rosmarinic acid derivative.

\section{Discussion}

Natural products exhibiting antimicrobial activity have been intensively studied in recent years. The subject of investigation is considered to be a hot topic, especially in the area of oral pathogens, due to increasing interests of consumers and patients towards pharmaceuticals of natural origin instead of synthetic ones. The question of oral hygiene is not only a matter of health but nowadays, it is considered to be an important part of overall well-being. In the light of the mentioned facts, numerous plant species and compounds isolated from them are tested for their activity against oral pathogenic strains. ${ }^{24,25}$ Tinctures made of plants have been examined for usage as mouthwash (Calendula officinalis and Echinacea angustifolia ${ }^{26}$ ginger alcoholic tincture ${ }^{27}$ ); however, according to the authors' best knowledge, this is the first study investigating the tincture of $N$. nuda as a potential mouthwash.

Both Listerine and $N$. nuda tincture showed promising antimicrobial potentials. No data are available from other researchers regarding the antimicrobial activity of $N$. nuda extracts; there is only some information about the antimicrobial activity of $N$. nuda essential oil. ${ }^{28}$ To the author's best knowledge, this is the first report on the antimicrobial activity of $N$. nuda tincture. Antimicrobial activities have been confirmed for $N$. nuda constituent rosmarinic acid. ${ }^{29,30}$ Rosmarinic acid was found to be active against following microorganisms: Staphylococcus epidermidis, Stenotrophomonas maltophilia, Enterococcus faecalis, Staphylococcus lugdunensis, Pseudomonas aeruginosa, Corynebacterium, Mycobacterium smeg- 
Table 3 Retention time $\left(R_{\mathrm{t}}\right)$, wavelengths of maximum absorption in the visible region $\left(\lambda_{\max }\right)$, mass spectral data, tentative identification and quantification of phenolic compounds in Nepeta nuda tincture

\begin{tabular}{|c|c|c|c|c|c|c|c|}
\hline Compounds & $R_{\mathrm{t}}(\min )$ & $\begin{array}{l}\lambda_{\max } \\
(\mathrm{nm})\end{array}$ & $\begin{array}{l}\text { Pseudomolecular } \\
\text { ion }[\mathrm{M}-\mathrm{H}]^{-}(\mathrm{m} / \mathrm{z})\end{array}$ & $\operatorname{MS}^{2}(m / z)$ & $\begin{array}{l}\text { Tentative } \\
\text { identification }\end{array}$ & Ref. & $\begin{array}{l}\text { Quantification } \\
\left(\mu \mathrm{g} \mathrm{mL} \mathrm{m}^{-1}\right)\end{array}$ \\
\hline 1 & 9.94 & $293, \operatorname{sh} 318$ & 685 & $\begin{array}{l}\text { 523(70), 361(100), 179(53), } \\
163(42), 135(15)\end{array}$ & Ligstroside hexoside $^{1}$ & Sanz et al. ${ }^{19}$ & $9.2 \pm 0.2$ \\
\hline 2 & 11.14 & $262, \operatorname{sh} 296$ & 497 & $\begin{array}{l}335(100), 221(33), 163(14), \\
153(22), 109(5)\end{array}$ & $\begin{array}{l}\text { Protocatechuic acid } \\
\text { derivative }^{2}\end{array}$ & $\begin{array}{l}\text { DAD, MS; Živković } \\
\text { et al. }\end{array}$ & $40.0 \pm 0.6$ \\
\hline 3 & 11.72 & 327 & - & $\begin{array}{l}359(100), 197(50), 161(5) \\
153(38), 135(18)\end{array}$ & $\begin{array}{l}\text { Rosmarinic acid } \\
\text { derivative }^{3}\end{array}$ & $\mathrm{DAD}, \mathrm{MS}$ & $25.8 \pm 0.2$ \\
\hline 4 & 12.71 & $291, \operatorname{sh} 327$ & 637 & $\begin{array}{l}\text { 491(5), 461(10), 351(100), } \\
\text { 193(50), 175(20), 161(10), } \\
\text { 135(5) }\end{array}$ & Eukovoside $^{1}$ & Sanz et al. ${ }^{19}$ & $9.6 \pm 0.4$ \\
\hline 5 & 13.49 & $289, \operatorname{sh} 328$ & 801 & $\begin{array}{l}639(100), 477(33), 315(60), \\
179(23), 161(17), 135(10)\end{array}$ & $\begin{array}{l}\text { Plantamajoside } \\
\text { hexoside }^{1}\end{array}$ & Gonda et $a .^{20}$ & $25.6 \pm 0.8$ \\
\hline 6 & 14.07 & $288, \operatorname{sh} 328$ & 639 & $\begin{array}{l}477(80), 315(100), 179(28) \\
161(38), 135(23)\end{array}$ & Plantamajoside $^{1}$ & $\begin{array}{l}\text { Gonda et al. }{ }^{20} \\
\text { Živković et al. }\end{array}$ & $12.1 \pm 0.4$ \\
\hline 7 & 15.28 & $289, \operatorname{sh} 328$ & 477 & $\begin{array}{l}315(23), 179(23), 161(100) \\
135(10)\end{array}$ & Calcelarioside $\mathrm{A} / \mathrm{B}^{1}$ & Sanz et al. ${ }^{19}$ & $6.98 \pm 0.08$ \\
\hline 8 & 16.51 & 325 & 453 & $\begin{array}{l}341(100), 281(20), 251(12) \\
221(3), 179(3)\end{array}$ & Caffeic acid derivative $^{3}$ & $\mathrm{DAD}, \mathrm{MS}$ & $17.9 \pm 0.8$ \\
\hline 9 & 16.98 & 319 & 523 & $\begin{array}{l}361(100), 343(20), 179(58) \\
163(63), 135(10)\end{array}$ & Verminoside $^{1}$ & Živković et al. ${ }^{21}$ & $115 \pm 4$ \\
\hline 10 & 18.2 & 336 & 717 & $\begin{array}{l}537(6), 519(99), 493(3) \\
359(100), 339(40), 321(4) \\
259(3), 197(31), 179(35)\end{array}$ & $\begin{array}{l}\text { Salvianolic acid B } \\
\text { isomer }^{3}\end{array}$ & Ribeiro et al. ${ }^{37}$ & $21.8 \pm 0.9$ \\
\hline 11 & 19.61 & 278 & 519 & $\begin{array}{l}339(20), 179(100), 161(5), \\
135(3)\end{array}$ & Caffeic acid derivative $^{3}$ & DAD, MS & $4.55 \pm 0.06$ \\
\hline 12 & 20.94 & 327 & 359 & $\begin{array}{l}\text { 197(28), 179(33), 161(100), } \\
135(3)\end{array}$ & Rosmarinic acid ${ }^{3}$ & $\begin{array}{l}\text { Comercial } \\
\text { standard, DAD, MS }\end{array}$ & $177 \pm 5$ \\
\hline 13 & 23.88 & 278 & 537 & $\begin{array}{l}\text { 493(22), 359(10), 313(9), } \\
\text { 295(100), 279(10), 197(10), } \\
\text { 179(33) }\end{array}$ & $\begin{array}{l}\text { Lithospermic acid A } \\
\text { isomer } 1^{3}\end{array}$ & $\begin{array}{l}\text { Ruan et al. }{ }^{38} \\
\text { Ribeiro } \text { et al. }{ }^{37}\end{array}$ & $14.1 \pm 0.4$ \\
\hline 14 & 24.82 & 278 & 537 & $\begin{array}{l}\text { 493(13), 359(10), 313(10), } \\
\text { 295(100), 279(8), 197(9), } \\
\text { 179(33) }\end{array}$ & $\begin{array}{l}\text { Lithospermic acid A } \\
\text { isomer } 2^{3}\end{array}$ & $\begin{array}{l}\text { Ruan et al. }{ }^{38} \\
\text { Ribeiro } \text { et al. }{ }^{37}\end{array}$ & $20.25 \pm 0.05$ \\
\hline \multirow[t]{2}{*}{15} & 26.81 & 283 & 717 & $\begin{array}{l}537(5), 519(100), 493(5), \\
359(3), 339(28), 321(88), \\
197(14), 179(10)\end{array}$ & $\begin{array}{l}\text { Salvianolic acid B } \\
\text { isomer } 2^{3}\end{array}$ & $\begin{array}{l}\text { Ruan et al. } ;^{38} \\
\text { Ribeiro } \text { et } a l .{ }^{37}\end{array}$ & $14.3 \pm 0.5$ \\
\hline & & & & & $\begin{array}{l}\text { Total phenolic } \\
\text { compounds }\end{array}$ & & $515 \pm 14$ \\
\hline
\end{tabular}

Calibration curves used: 1 - caffeic acid $\left(y=388345 x+406369 ; R^{2}=0.994\right) ; 2$ - protocatechuic acid $\left(y=214168 x+27102 ; R^{2}=0.999\right) ; 3$ - rosmarinic acid $\left(y=191291 x-652903 ; R^{2}=0.99\right)$.

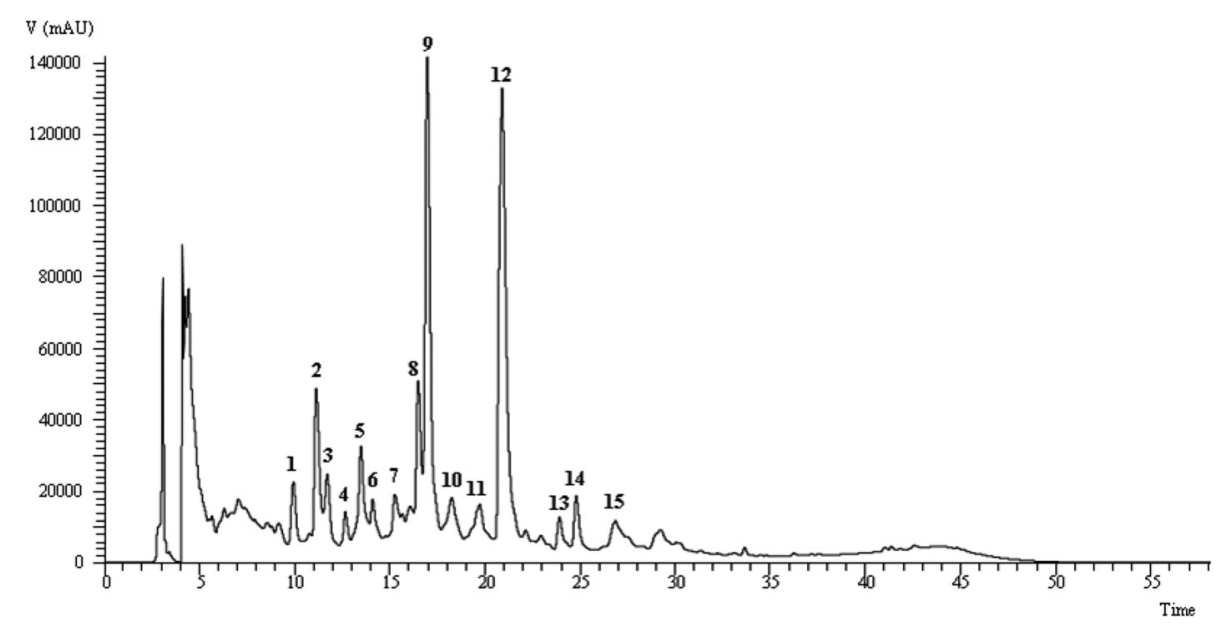

Fig. 3 Phenolic composition of Nepeta nuda tincture recorded at $280 \mathrm{~nm}$. Numbers correspond to the compounds present in Table 3 . 
matis, and Staphylococcus warneri. Rosmarinic acid exhibited MIC of 0.3 and MBC 0.6 of $\mathrm{mg} \mathrm{mL}^{-1},{ }^{30}$ whereas $N$. nuda tincture had MIC of $3.1 \mathrm{mg} \mathrm{mL} \mathrm{mL}^{-1}$ and $\mathrm{MBC}$ of $6.2 \mathrm{mg} \mathrm{mL}$ towards different strains of E. faecalis species. Although rosmarinic acid as the main constituent of the tincture is present in $3.5 \%$ of the total amount of tincture, the MIC values are only 10 times higher when compared with previous values and MIC values for pure compound. One of the advantages of using extracts in biological purposes is synergistic activity of the mixture of compounds that is naturally present in living species.

When oral hygiene is neglected, bacterial species group and form biofilms. Since the formation of a biofilm is the initial step that leads towards bacterial overgrowth and spreading of infection, both mouthwashes were tested to compare their ability to prevent bacteria to embed in these pathogenic groupings. $S$. pyogenes and $E$. faecalis were chosen as representative biofilm-forming strains in this experiment. $N$. nuda tincture in concentration of $0.75 \mathrm{mg} \mathrm{mL} \mathrm{mL}^{-1}$ (1/2 MIC) could prevent biofilm formation in high percentage (84\%). Some future study might explore the potential of $N$. nuda essential oil as an antibiofilm agent. $N$. nuda ticture (1/2 MIC or $1.55 \mathrm{mg} \mathrm{mL}^{-1}$ ) could also prevent $E$. faecalis from biofilm formation after $24 \mathrm{~h}$ exposure. Hypericum perforatum extracts showed better activity and inhibited biofilm formation when applied in concentrations of 7.23-29.91 $\mu \mathrm{g} \mathrm{mL} \mathrm{mL}^{-1}{ }^{31}$ Euphorbia hirta extracts showed promising antibiofilm activity in concentration of $0.5 \mathrm{mg} \mathrm{mL}{ }^{-1} .^{32}$ Some extracts from the plants of Amazon rain forest and Atlantic forest are active in preventing biofilm formation in the concentration of $3 \mathrm{mg} \mathrm{mL}^{-1}$. $^{33}$

The most resistant strain in microdilution test, i.e., E. faecalis was chosen as a model to investigate the ability of these two mouthwashes to destroy the bacterial biofilm when it is already formed. This established biofilm was found to be highly resistant since after $30 \mathrm{~s}$ of treatment, none of the preparations at concentrations of MIC and 1/2 MIC could demolish it for more than $50 \%$. Listerine was more effective in the biofilm reduction after $30 \mathrm{~s}$ when compared to $N$. nuda tincture; however, $N$. nuda was more prominent and had higher inhibition values than Listerine after $60 \mathrm{~s}$. The activity of Listerine was almost unchanged regarding the duration of treatment in contrast to that of $N$. nuda; its biofilm reduction activity rose with the prolongation of treatment.

To the best of our knowledge, this is the first study reporting the potential of Nepeta nuda tincture to interfere with microbial biofilms in contrast to that of Listerine, which has been proven as an antibiofilm agent. ${ }^{6,34}$ Listerine with other mouthwashes such as those based on chlorhexidine and octenidine has been shown to be effective in reducing cariogenic plaque in clinical trials with patients with fixed orthodontic appliances ${ }^{35}$ but currently, there is no research concerning the clinical implication of $N$. nuda tincture.

Rosmarinic acid and verminoside were the most abundant compounds present. To the author's best knowledge, this is the first report describing phenylethanoid glycosides and caffeoyl derivatives in $N$. nuda. Nevertheless, there are few pre- vious studies that have described rosmarinic acid as one of the most abundant compounds in this species. ${ }^{22,23,36}$

\section{Conclusions}

Both Listerine and $N$. nuda tincture $\left(100 \mathrm{mg} \mathrm{mL}^{-1}\right)$ exhibited high efficacies in combating a selected group of oral pathogens. Based on their antimicrobial activities, the use of either one of them for $30 \mathrm{~s}$ gurgling with $20 \mathrm{~mL}$ of liquid could be recommend. However, in case of problems with bacteria that have biofilm forming ability, $N$. nuda tincture is highly recommended since it showed much better potential to inhibit the formation of biofilms. Taking into account all the experimental results, it would be more desirable to swish mouthwashes (Listerine and $N$. nuda tincture) for $30 \mathrm{~s}$ when dealing with selected microorganisms in general and for $60 \mathrm{~s}$ (N. nuda tincture) when dealing with bacterial biofilms. Since $N$. nuda is widely used in ethnomedicine, it is considered as generally safe for oral application without swallowing. Chemical profiling of $N$. nuda tincture showed rosmarinic acid and verminoside as the most dominant phenolic compounds. Considering that (i) phenolic compounds found in plant species are generally considered as non-toxic to humans and (ii) the mode of application of the newly designed antimicrobial mouthwash product based on the plant extract, we recommend $N$. nuda tincture as a safe mouthwash for human usage. Nevertheless, further clinical studies are necessary to confirm these findings and enlighten these predictions for the usage of $N$. nuda tincture as a mouthwash.

\section{Conflicts of interest}

The authors declare no conflict of interests.

\section{Acknowledgements}

This work has been supported by the Serbian Ministry of Education, Science and Technological Development for financial support (Grant number 173032 and 173029). The authors are grateful to the Foundation for Science and Technology (FCT) of Portugal and FEDER under Programme PT2020 for financial support to CIMO (UID/AGR/00690/2013) and L. Barros research contract. The authors are grateful to FEDER-Interreg España-Portugal programme for financial support through the project 0377_Iberphenol_6_E.

\section{References}

1 K. H. C. Baser, N. Kirimer, M. Kurkcuoglu and B. Demirci, Essential oils of Nepeta species growing in Turkey, Chem. Nat. Compd., 2000, 36(4), 356-359.

2 I. Süntar, S. M. Nabavi, D. Barreca, N. Fischer and T. Efferth, Pharmacological and chemical features of 
Nepeta L. genus: its importance as a therapeutic agent, Phytother. Res., 2018, 32(2), 185-198.

3 A. Dogan and E. Tuzlaci, Wild edible plants of Pertek (Tunceli-Turkey), Marmara Pharm. J., 2015, 19, 126-135.

4 A. Leszczyńska, P. Buczko, W. Buczko and M. Pietruska, Periodontal pharmacotherapy - an updated review, Adv. Med. Sci., 2011, 56(2), 123-131.

5 S. R. Porter and C. Scully, Oral malodour (halitosis), Br. Med. J., 2006, 333(7569), 632-635.

6 V. Quintas, I. Prada-López, M. J. Carreira, D. SuárezQuintanilla, C. Balsa-Castro and I. Tomás, In situ antibacterial activity of essential oils with and without alcohol on oral biofilm: a randomized clinical trial, Front. Microbiol., 2017, 8, 2162.

7 B. Kouidhi, T. Zmantar, K. Mahdouani, H. Hentati and A. Bakhrouf, Antibiotic resistance and adhesion properties of oral Enterococci associated to dental caries, $B M C$ Microbiol., 2011, 11, 155.

8 T. E. Rams, D. Feik, J. E. Mortensen, J. E. Degener and A. J. van Winkelhoff, Antibiotic susceptibility of periodontal Enterococcus faecalis, J. Periodontol., 2013, 84(7), 1026-1033.

9 W. J. Loesche, Role of Streptococcus mutans in human dental decay, Microbiol. Rev., 1986, 50(4), 353-380.

10 B. J. Paster, I. Olsen, J. A. Aas and F. E. Dewhirst, The breadth of bacterial diversity in the human periodontal pocket and other oral sites, Periodontology, 2000, 42, 80-87.

11 A. G. Manetti, C. Zingaretti, F. Falugi, S. Capo, M. Bombaci, F. Bagnoli, et al., Streptococcus pyogenes pili promote pharyngeal cell adhesion and biofilm formation, Mol. Microbiol., 2007, 64(4), 968-983.

12 J. Delaloye and T. Calandra, Invasive candidiasis as a cause of sepsis in the critically ill patient, Virulence, 2014, 5(1), 161-169.

13 S. Patil, R. S. Rao, B. Majumdar and S. Anil, Clinical appearance of oral candida infection and therapeutic strategies, Front. Microbiol., 2015, 6, 1391.

14 K. D. Douk, S. Dagher and E. Sattout, Antifungal activity of the essential oil of Origanum syriacum L., J. Food Prot., 1995, 58, 1147-1149.

15 EUCAST (European Committee on Antibiotic Susceptibility), Method for determination of minimal inhibitory concentration (MIC) by broth dilution of fermentative yeasts. Discussion document E. Dis. 7.1. European Society of Clinical Microbiology and Infectious Diseases, Taufkirchen, Germany, 2002.

16 E. Drenkard and F. M. Ausubel, Pseudomonas biofilm formation and antibiotic resistance are linked to phenotypic variation, Nature, 2002, 416, 740-743.

17 C. G. Pierce, P. Uppuluri, A. R. Tristan, F. L. Wormley Jr., E. Mowat, G. Ramage and J. L. Lopez-Ribot, A simple and reproducible 96-well plate-based method for the formation of fungal biofilms and its application to antifungal susceptibility testing, Nat. Protoc., 2008, 3, 1494-1500.

18 S. M. F. Bessada, J. Barreira, L. Barros, I. C. F. R. Ferreira and B. Oliveira, Phenolic profile and antioxidant activity of Coleostephus myconis (L.) Rchb.f.: An underexploited and highly disseminated species, Ind. Crops Prod., 2016, 89, 4551.

19 M. Sanz, B. F. de Simón, E. Cadahía, E. Esteruelas, A. M. Muñoz, T. Hernández, et al., LC-DAD/ESI-MS/MS study of phenolic compounds in ash (Fraxinus excelsior L. and F. americana L.) heartwood. Effect of toasting intensity at cooperage, J. Mass Spectrom., 2012, 47, 905-918.

20 S. Gonda, A. Kiss-Szikszai, Z. Szűcs, C. Máthé and G. Vasas, Effects of $\mathrm{N}$ source concentration and $\mathrm{NH} 4+/ \mathrm{NO} 3$ ratio on phenylethanoid glycoside pattern in tissue cultures of Plantago lanceolata L.: A metabolomics driven full-factorial experiment with LC-ESI-MS3, Phytochemistry, 2014, 106, 44-54.

21 J. Č. Živković, J. C. M. Barreira, K. P. Šavikin, A. Z. Alimpić, D. S. Stojković, M. I. Dias, C. Santos-Buelga, S. N. DuletićLaušević and I. C. F. R. Ferreira, Chemical profiling and assessment of antineurodegenerative and antioxidant properties of Veronica teucrium L. and Veronica jacquinii Baumg, Chem. Biodiversity, 2017, 14(8), e1700167.

22 J. Cvetković, M. Milutinovic, J. Boljevic, N. Anicic, J. Nestorovic Zivkovic, S. Zivkovic and D. Misic, Paraquatmediated oxidative stress in Nepeta pannonica L., Bot. Serb., 2015, 39, 121-128.

23 A. Aras, E. Bursal and M. Dogru, UHPLC-ESI-MS/MS analyses for quantification of phenolic compounds of Nepeta nuda subsp. Lydiae, J. Appl. Pharm. Sci., 2016, 6, 9-13.

24 M. Smiljkovic, D. Stanisavljevic, D. Stojkovic, I. Petrovic, J. Marjanovic Vicentic, J. Popovic, et al., Apigenin-7-O-glucoside versus apigenin: Insight into the modes of anticandidal and cytotoxic actions, EXCLI J., 2017, 16, 795-807.

25 M. Smiljković, M. Kostic, D. Stojkovic, J. Glamoclija and M. Sokovic, Could flavonoids compete with synthetic azoles in diminishing Candida albicans infections? A comparative review based on in vitro studies, Curr. Med. Chem., 2018, DOI: $10.2174 / 0929867325666180629133218$, In press.

26 M. P. De Diego, Homeopathic mother tinctures from Calendula officinalis and Echinacea angustifolia as oral antiseptics, Rev. Med. Homeopat., 2013, 6(3), 112-126.

27 I. Jain, P. Jain, D. Bisht, A. Sharma, B. Srivastava and N. Gupta, Use of traditional Indian plants in the inhibition of caries-causing bacteria-Streptococcus mutans, Braz. Dent. J., 2015, 26(2), 110-115.

28 A. Gormez, S. Bozari, D. Yanmis, M. Gulluce, G. Agar and F. Sahin, Antibacterial activity and chemical composition of essential oil obtained from Nepeta nuda against phytopathogenic bacteria, J. Essent. Oil Res., 2013, 25(2), 149153.

29 H. P. Bais, T. Walker, H. Schweizer and J. Vivanco, Root specific elicitation and antimicrobial activity of rosmarinic acid in hairy root cultures of Ocimum basilicum, Plant Physiol. Biochem., 2002, 40, 983-995.

30 A. Abedini, V. Roumy, S. Maxieux, M. Biabiany, A. Standaert-Vitse, C. Riviere, et al., Rosmarinic acid and its methyl ester as antimicrobial components of the hydromethanolic extract of Hyptis atrorubens Poit. (Lamiaceae), Evid-Based Compl. Alt., 2013, 604536. 
31 I. Süntar, O. Oyardı, E. K. Akkol and B. Ozçelik, Antimicrobial effect of the extracts from Hypericum perforatum against oral bacteria and biofilm formation, Pharm. Biol., 2016, 54(6), 1065-1070.

32 S. Perumal and R. Mahmud, Chemical analysis, inhibition of biofilm formation and biofilm eradication potential of Euphorbia hirta L. against clinical isolates and standard strains, BMC Complementary Altern. Med., 2013, 13, 346.

33 A. L. Castilho, C. H. Saraceni, I. E. Díaz, M. L. Paciencia and I. B. Suffredini, New trends in dentistry: plant extracts against Enterococcus faecalis. The efficacy compared to chlorhexidine, Braz. Oral Res., 2013, 27(2), 109-115.

34 I. Prada-López, V. Quintas, M. A. Casares-De-Cal, J. A. Suárez-Quintanilla, D. Suárez-Quintanilla and I. Tomás, Ex vivo vs. in vivo antibacterial activity of two antiseptics on oral biofilm, Front. Microbiol., 2015, 2(6), 655.

35 M. M. Pithon, L. I. Sant'Anna, F. C. Baião, R. L. dos Santos, S. Coqueiro Rda and L. C. Maia, Assessment of the effec- tiveness of mouthwashes in reducing cariogenic biofilm in orthodontic patients: a systematic review, J. Dent., 2015, 43(3), 297-308.

36 L. Dienaitè, M. Pukalskienè, A. A. Matias, C. V. Pereira, A. Pukalskas and P. R. Venskutonis, Valorization of six Nepeta species by assessing the antioxidant potential, phytochemical composition and bioactivity of their extracts in cell cultures, J. Funct. Foods, 2018, 45, 512-522.

37 A. Ribeiro, C. Caleja, L. Barros, C. Santos-Buelga, M. F. Barriero and I. C. F. R. Ferreira, Rosemary extracts in functional foods: extraction, chemical characterization and incorporation of free and microencapsulated forms in cottage cheese, Food Funct., 2016, 7, 2185-2196.

38 M. Ruan, Y. Li, X. Li, J. Luo and L. Kong, Qualitative and quantitative analysis of the major constituents on Chinese medicinal preparation Guan-Xin-Ning injection by HPLC-DAD-ESI-MSn, J. Pharm. Biomed., 2012, 59, 184-189. 